\title{
An asymptomatic patient with abandoned leads. Shall we wait decades for class I indications or is it time to consider prophylactic lead extraction?
}

\author{
Wojciech Borzęcki ${ }^{1, \mathrm{~A}, \mathrm{D}}$, Andrzej Wacław Kutarski, ${ }^{1, \mathrm{~B}-\mathrm{C}, \mathrm{F}}$, Paweł Stefańczyk ${ }^{1, \mathrm{~B}}$, Konrad Tomkow ${ }^{1, \mathrm{~B}}$, \\ Dorota Nowosielecka $^{1, C}$, Lukasz Tułecki ${ }^{1, C}$, Andrzej Kleinrok ${ }^{1, C}$ \\ A - Research concept and design, B - Collection and/or assembly of data, C - Data analysis and interpretation, \\ D - Writing the article, E - Critical revision of the article, F - Final approval of article
}

1. The Pope John Paul II Province Hospital of Zamosc

Address for correspondence:

Wojciech Borzęcki, The Pope John Paul II Province Hospital of Zamosc email: wojtek.borz@gmail.com

Andrzej Wacław Kutarski, The Pope John Paul II Province Hospital of Zamosc email: a_kutarski@yahoo.com

Paweł Stefańczyk, The Pope John Paul II Province Hospital of Zamosc email: paolost@interia.pl

Konrad Tomkow, The Pope John Paul II Province Hospital of Zamosc email: konradtomkow@wp.pl

Dorota Nowosielecka, The Pope John Paul II Province Hospital of Zamosc email: dornowos@wp.pl

Lukasz Tułecki, The Pope John Paul II Province Hospital of Zamosc email: luke27@poczta.onet.pl

Andrzej Kleinrok, The Pope John Paul II Province Hospital of Zamosc mail: a.kleinrok@wp.pl

Received: 2019-05-06

Revised: 2019-05-21

Accepted: 2019-05-25

Final review: 2019-05-25

DOI: $10.24255 / \mathrm{hbj} / 109633$

\section{Key words:}

cardiac surgery, transvenous lead extraction, complications of lead extraction

\section{Summary}

For the last 20 years scientific guidelines have suggested either lead abandonment or extraction in cardiac implantable electronic device (CIED) patients (class $2 b$ indications). The former strategy, especially in people with longer life expectancy, produces a population of subjects in whom years after device implantation transvenous lead extraction (TLE) becomes a harmful procedure although it appears the only choice in patients with class 1 indications. We describe a female patient with four leads, including two that were abandoned 20 years ago, with pocket infection and lead-related infective endocarditis in whom the sum of the ages of all leads was 100

\section{Introduction}

There has always been controversy over long-term management of superfluous leads (dysfunctional or potentially years (in our opinion the risk associated with removal of old leads is cumulative). The extraction procedure performed in the maximally safe environment was successful. All the leads were removed, and a major complication, cardiac tamponade, was managed surgically by placing sutures over two large perforations in the right atrial appendage (RAA). We discuss the course of the disease and investigate the possible outcomes of TLE if it had been performed 12 years earlier when replacing the device. We also discuss late and very late consequences of lead abandonment on the basis of this case report.

functional but redundant). The view that retaining rather than extracting unused leads is associated with a lower risk of complications has been known since the publication of 
the North American Society of Pacing and Electrophysiology (NASPE) policy statement in $2000^{[1]}$. A number of studies have supported this treatment strategy, suggesting that superfluous or abandoned leads do not increase the risk of death at short-term follow-up ${ }^{[2-4]}$. There are no, and there will probably never be, long-term randomized studies assigning patients to lead abandonment or extraction. Nevertheless, multiple small single-center clinical trials and case reports have demonstrated various complications due to abandoned leads that would appear many years later $[5,6,7,8,9,9]$.

According to the 2009 Heart Rhythm Society (HRS) guidelines, both strategies are considered equivalent ${ }^{[10]}$ if the lead does not pose a threat to the patient. "Prophylactic" lead extraction (in order to avoid late consequences of long-term abandonment of superfluous leads or to save the veins on the contralateral side of the chest for other medical procedures) may be considered but only after taking into account potential threats due to lead abandonment (class $2 \mathrm{~b}$ indications). Although it is relatively easy to estimate the risk of transvenous lead extraction (understood as the risk of major complications during and after the procedure) the risk of lead abandonment remains unknown ${ }^{[11,12,13]}$. However, the evidence is accumulating for late complications in those with abandoned leads going in ${ }^{[14,125,16]}$.

It is widely acknowledged that the number of complications during lead removal increases with increasing lead dwell times $^{[17,18,19,20,21]}$. The risk of failed extraction doubles every 3 years of implant duration. A serious problem may appear in future when the unit with retained wires must be removed due to infection or in order to regain access to the venous circulation for placement of new leads (class 1/2a indications). Then the presence of the abandoned leads is more challenging (larger vegetations, poorer prognosis, more complications, more complex procedure $)^{[14]}$.

There is abundant evidence confirming the increased risk of both regional and generalized infections in patients with abandoned leads ${ }^{[21,22,23]}$. Abrasion on endocardial lead insulations is a well-known phenomenon. The more leads in the heart, the more likely it is to occur ${ }^{[5,24]}$. The presence of abandoned leads is now considered a relative contraindication for magnetic resonance imaging, and if MRI is mandatory, the lead should be removed prior to the examination ${ }^{[25]}$.

The presence of more than four leads in the subclavian vein or more than five leads in the superior vena cava increases the risk of thrombosis or venous stenosis and in compliance with the 2009 HRS expert consensus is unacceptable $\mathrm{e}^{[10,25]}$.

Abandoned leads, both functional and dysfunctional, dislocated and twisted, may contribute to tricuspid valve failure ${ }^{[26]}$.

Taking into account advances in lead extraction technology and various approaches to lead abandonment, we should not be surprised by clinical heterogeneity in patients with retained leads and the number of problems encountered during patient management. Due to longer life expectancy of the population, including the patients with CIEDs, we encounter in clinical practice a number of subjects with leads that were abandoned at the time when in some European countries transvenous lead extraction was not a common procedure. Although intravas- cular techniques for extraction of permanent pacemaker leads were introduced by Charles Byrd in $1990^{[27]}$, the procedure was first performed in Poland at the end of the 1990s. Nevertheless, superfluous or dysfunctional leads were left in place in most patients. Some of these patients with multiple leads, young at the time of implantation, have survived until today, posing a major challenge for operators, especially if there are class 1 indications (infection) for removal of the device and all abandoned leads. Surgical intervention is frequently impossible as the leads often adhere to the vascular walls of the subclavian vein, innominate vein and superior vena cava, making them practically inaccessible for cardiac surgeons. Transvenous lead extraction appears the only choice with the awareness of a significant risk for developing major complications (mainly cardiac tamponade).

\section{Case description}

Herein we describe a female patient whose rich pacemaker-related medical history is an excellent example of lead abandonment issues and challenges. It is commonly known that female gender, the need for extraction of multiple leads and long lead dwell time (the sum of the ages of all leads was 100 years in this case) are significant predictors of major complications ${ }^{[17,18,19,20,21]}$. However, if infection ensues, the appropriate treatment cannot be denied.

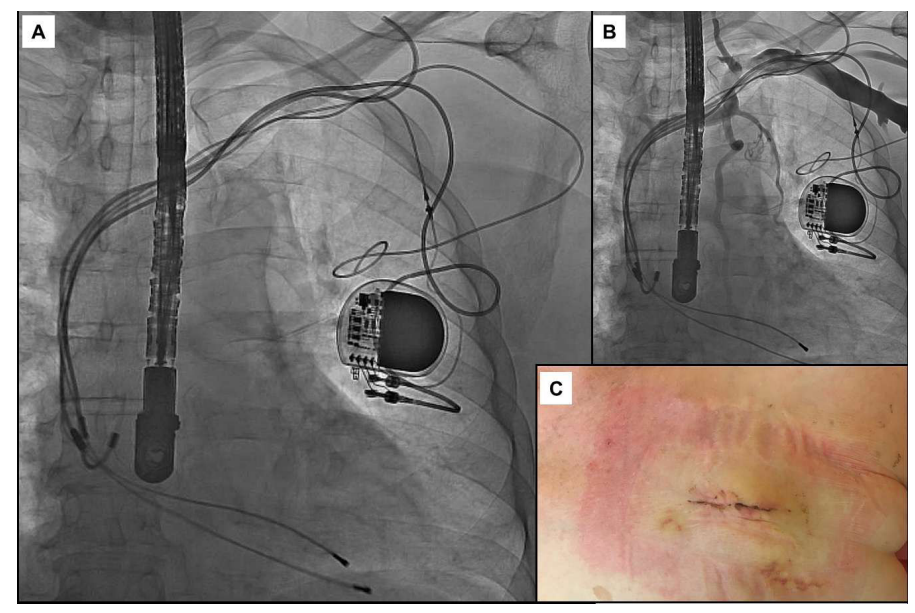

Figure1. Old DDD pacing system with two abandoned leads. (A). Venous occlusion (B) Pocket infection without draining sinus (C).

This 65-year-old woman was referred to the tertiary care hospital with the symptoms of pocket infection (a DDD system with two unused leads) which developed after device replacement due to battery depletion in 2017. A VVI unipolar lead pacemaker was primarily implanted in 1988 due to sinus node disease. A year later two revisions were made: to place the device under the pectoralis major muscle because of the painful pacemaker pocket, and to implant a new unipolar lead in the right ventricle due to diaphragmatic stimulation. In 1991 the pacing mode was changed to AAI (with a unipolar lead placed in the right atrial appendage) due to pacemaker syndrome, and 5 years later the device was upgraded to the DDD system using the old right ventricular lead.

Between 1999 and 2007 the patient underwent atrial and ventricular lead repair, implantation of a new right atrial bi- 


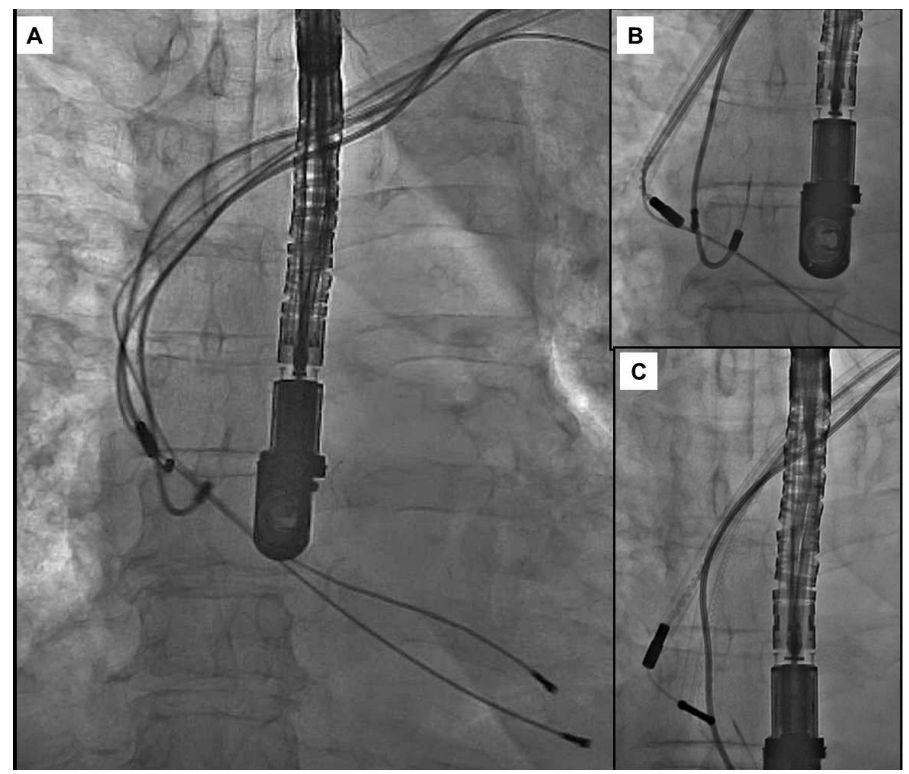

Figure2. First attempt to remove UP ventricular lead (A). Strong lead-to-lead adhesion with connective tissue scar (B), another technique necessary. Attempt of separation of both leads using simultaneously two Byrd dilators (C)

polar lead, pacemaker replacement due to battery depletion and two revisions because of a sore near the implant site and a painful pacemaker pocket.

\begin{tabular}{|c|c|}
\hline \multicolumn{2}{|c|}{ Timetable of clinical events } \\
\hline 1988 & $\begin{array}{l}\text { Implantation of VVI system due to SND (UP Siemens } \\
\text { lead implanted in RVA) }\end{array}$ \\
\hline 1989 & $\begin{array}{l}\text { Implantation of a new UP Siemens lead in RVA due to } \\
\text { primary lead dysfunction }\end{array}$ \\
\hline 1991 & $\begin{array}{l}\text { Change of pacing mode to AAI due to "pacemaker syn- } \\
\text { drome". Lack of DDD units in those days. A new lead } \\
\text { (Target Tip) implanted in RAA }\end{array}$ \\
\hline 1996 & $\begin{array}{l}\text { System upgrade. A new DDD unit (Dromos) connected } \\
\text { to atrial and previously abandoned UP ventricular lead }\end{array}$ \\
\hline 1999 & Unit reimplantation due to battery exhaustion \\
\hline 2000 & $\begin{array}{l}\text { Dysfunction of both previously functional leads and } \\
\text { implantation of a new bipolar lead in RAA, and the } \\
\text { connector (A1N) used for UP ventricular lead }\end{array}$ \\
\hline 2007 & Simple unit (DDD) replacement \\
\hline 2007 & Two pocket revisions due to local surgical problems \\
\hline 2007 & $\begin{array}{l}\text { Two hospitalizations due to fever of unclear origin. } \\
\text { Lead-related endocarditis was suspected but the } \\
\text { patient improved after antibiotics. }\end{array}$ \\
\hline 2017 & $\begin{array}{l}\text { Simple unit replacement, followed by symptoms of } \\
\text { pocket infection. The patient was sent for removal of } \\
\text { the whole system to the high-volume TLE center. }\end{array}$ \\
\hline 2017 & $\begin{array}{l}\text { Removal of the whole system. Normal sinus rhythm } \\
\text { with episodic insignificant bradycardia. No prolonged } \\
\text { temporary pacing. Antibiotic therapy continued accord- } \\
\text { ing to the guidelines for lead-related endocarditis. Full } \\
\text { recovery. } \\
\text { Holter monitoring on several occasions - no indica- } \\
\text { tions for cardiac pacing }\end{array}$ \\
\hline 2019 & $\begin{array}{l}\text { Telephone contact with the patient (and her doctor). } \\
\text { Good general condition, implantation of a new pacing } \\
\text { system was not necessary. }\end{array}$ \\
\hline
\end{tabular}

The symptoms of pocket infection developed a few days after replacement of the device.

Pacemaker explantation and removal of unused leads were performed under general anesthesia in a hybrid operating room at our hospital with on-site cardiac surgery backup. The lead extraction procedure was carried out under the guidance of transesophageal echocardiography (baseline examination revealed wall motion of the superior vena cava with all ingrown leads). Several abscesses were detected in the pacemaker pocket and along the leads.

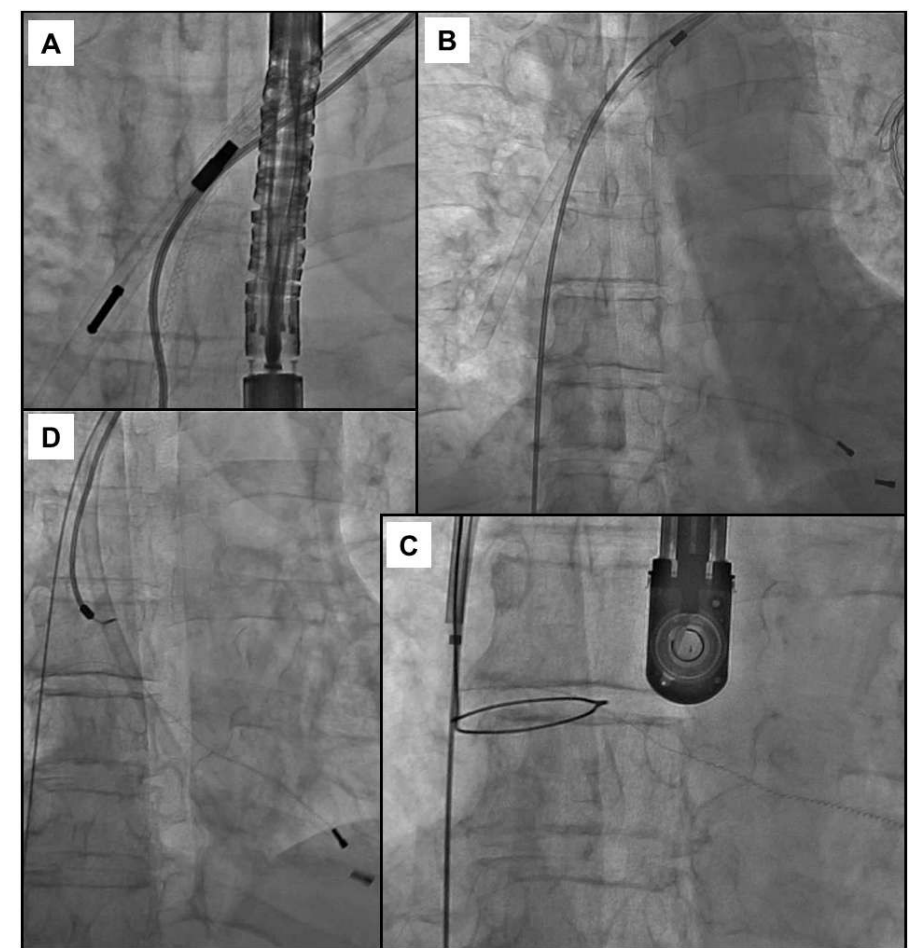

Figure3. Atrial lead extracted (A), but both old UP ventricular leads were broken (B). Both lead remnants were successively grasped with a lasso catheter (C) and extracted using Byrd dilators (D). At this step of the procedure cardiac tamponade was recognized and urgent sternotomy was performed. Bleeding place in RAA was closed and lead extraction procedure was continued keeping open the chest for external monitoring of lead extraction. Extracorporeal circulation was not used.

During the extraction of the atrial lead with a shorter dwell time the atrial wall was perforated and cardiac tamponade ensued. Immediate sternotomy and sutures placed on the perforation site prevented pressure drop. The remaining leads were extracted with the pericardium being open. Both ventricular leads were broken. A lasso catheter was used to capture the lead tips for removal in the manner described by the authors elsewhere ${ }^{[28-30]}$. After the extraction of all leads, in preparation for sternal closure, another, smaller, perforation in the atrial wall was noticed and it was also managed.

The patient was moved to a recovery room, and a few hours later she was woken up and extubated. No surgery-related neurological deficits were found.

The patient received targeted antibiotic therapy (atrial lead tip culture positive for Staphylococcus haemolyticus). On the seventh day the patient in good general condition was transferred to the parent hospital for continuation of her treatment.

The patient is still doing well without the pacemaker and four leads. 


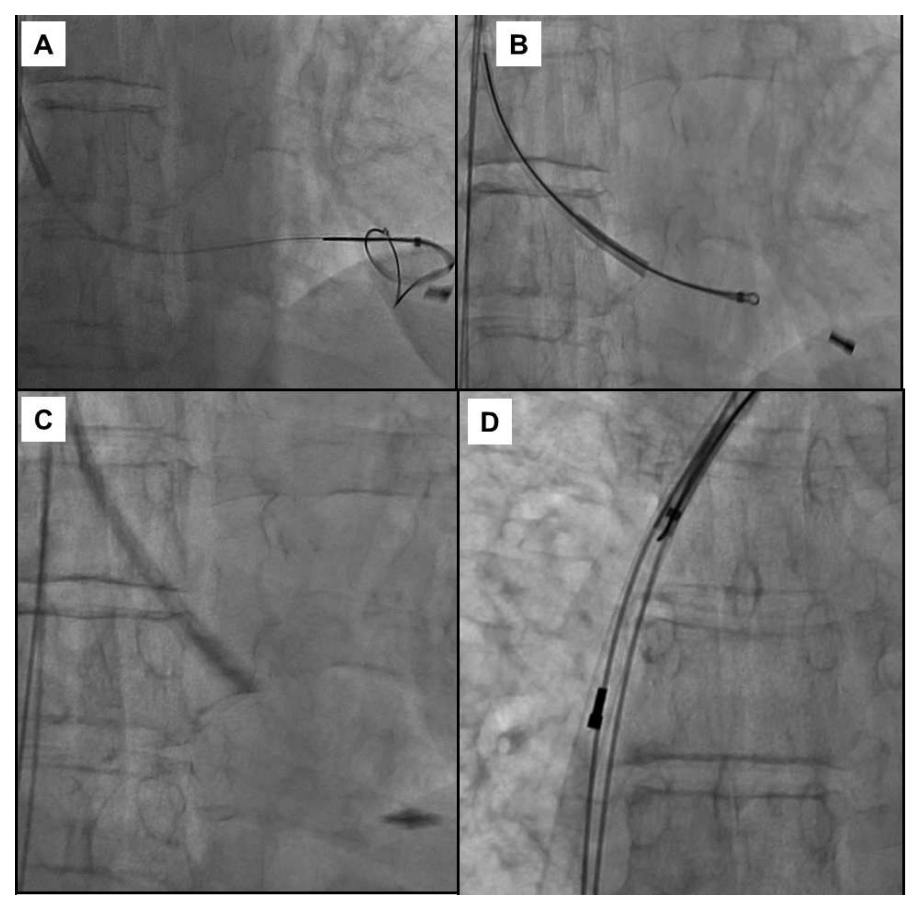

Figure4. Second ventricular lead remnant fragment was grasped with a lasso $(A, B)$ and extracted with Byrd dilator (CD)

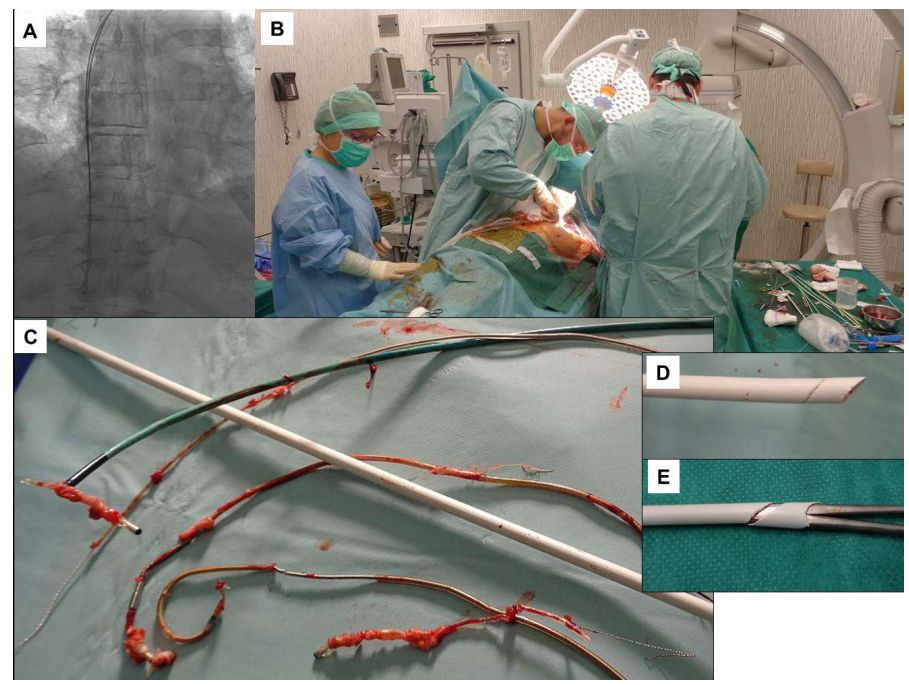

Figure5. Finally all leads were completely removed (A). The second bleeding point in RAA was diagnosed and sutured. The chest was closed (B). All lead fragments and their tips are visible on the table (C). A strange, rare and potentially dangerous form of Byrd dilator damage.

\section{Final observations}

The present case study is a good example of complications that patients with abandoned leads can be exposed to and of technical problems which may be encountered during TLE procedures. The first serious technical problem was encapsulation of the leads by connective tissue (fibrous tissue adhesions) at the level of the high right atrium. The problem was solved by using simultaneously two sets of Byrd dilators (the technique applied for years by the authors in similar cases). Another problem was pericardial tamponade which interrupted the extraction procedure only for a while. A nonstandard but practicable approach was to manage the tamponade and continue transvenous lead extraction with the open chest and pericardium. In this way it was possible to observe the outside of the heart and the SVC and to intervene immediately, if necessary. As a matter of fact, due to delayed sternal closure it was possible to detect bleeding from another small perforation made by the tip of the second atrial lead. The interesting part of the procedure was grasping fragments of the torn leads by a lasso catheter looped around the coronary sinus catheter with bent tip and inserted into the heart. The lead fragment, snare lasso and CS catheter formed a slide over which Byrd dilators were placed in the heart to continue separation of the torn lead from the RV wall. All the technical problems were overcome with the experience of the operator and the whole team (the 2544th procedure in the authors' database).

The reasons for unit explantation were obvious. Infection is a class 1 indication. Perhaps, if earlier (for instance in 2007 when TLE procedures became available in our hospital) it had been decided to remove the unused leads, the patient would have avoided infection and a complex TLE procedure. However, the concept of prophylactic extraction of superfluous leads in the absence of complications has not gained widespread acceptance as yet.

\section{References}

1. Love CJ, Wilkoff BL, Byrd CL, et al. Recommendations for extraction of chronically implanted transvenous pacing and defibrillator leads: indications, facilities, training. North American Society of Pacing and Electrophysiology Lead Extraction Conference Faculty. Pacing Clin. Electrophysiol. 2000;23:544-51

2. Glikson M, Suleiman M, Luria DM, et al. Do abandoned leads pose risk to implantable cardioverter-defibrillator patients? Heart Rhythm. 2009; 6: 65-68

3. Silvetti MS, Drago F, Outcome of young patients with abandoned, nonfunctional endocardial leads. Pacing Clin. Electrophysiol. 2008;31:473-479

4. Rijal S, Shah RU, Saba S. Extracting versus abandoning sterile pacemaker and defibrillator leads. Am. J. Cardiol. 2015; 115:1107-1110.

5. Kutarski A, Małecka B, Kołodzinska A, Grabowski M. Mutual abrasion of endocardial leads: analysis of explanted leads. Pacing Clin Electrophysiol. 2013 ;36:1503-1501

6. Polewczyk M, Tomków K, Tułecki Ł, Polewczyk A, Młynarczyk K, Kutarski A. Abandoned pacing lead - a trap and a source of subsequent technical complications during transvenous lead extraction. Heart Beat Journ. 2018;3:90-92

7. Polewczyk AM, Polewczyk M, Kutarski A. 15-year-old atrial pacing lead displaced into pulmonary artery - the consequences of prolonged observation. Heart Beat Journ, 2016;1:28-30

8. Böhm A, Pintér A, Duray G, et al. Complications due to abandoned noninfected pacemaker leads. Pacing Clin. Electrophysiol. 2001;24:1721-724.

9. Pokorney SD, Mi X, Lewis RK, et al. Outcomes associated with extraction versus capping and abandon- 
ing pacing and defibrillator leads. Circulation. 2017; 10;136:1387-1395.

10. Wilkoff BL, Love CJ, Byrd CL, et al. Heart Rhythm Society, American Heart Association. Transvenous lead extraction: Heart Rhythm Society expert consensus on facilities, training, indications, and patient management: this document was endorsed by the American Heart Association (AHA). Heart Rhythm. 2009; 6: 1085-1104.

11. Kancharla K, Acker NG, Li Z, et al. Efficacy and safety of transvenous lead extraction in the device laboratory and operating room guided by a novel risk stratification scheme. JACC Clin Electrophysiol. 2019 Feb;5(2):174-182.

12. Jacheć W, Polewczyk A, Polewczyk M, Tomasik A, Janion M, Kutarski A. Risk factors predicting complications of transvenous lead extraction. Biomed Res Int. 2018 Dec 18;2018:8796704

13. Segreti L, Giannotti Santoro M, Di Cori A, et al. Utility of risk scores to predict adverse events in cardiac lead extraction. Expert Rev Cardiovasc Ther. 2018;16:695705.

14. Hussein A, K Tarakji K, W Saliba W. Cardiac implantable electronic device infection: variability in clinical presentation and outcomes in patients with or without previously abandoned leads. JACC Clin Electrophysiol. 2017; 3: 1-9.

15. Trucco E, Mont L. Extraction of sterile leads is the preferred approach rather than implanting a new lead: the con perspective. Card ElectrophysiolClin. 2015; 7: 427-31

16. Huang $\mathrm{XM}, \mathrm{Fu} \mathrm{H}$, Osborn MJ, et al. Extraction of superfluous device leads: A comparison with removal of infected leads. Heart Rhythm. 2015; 12: 1177-82

17. Wilkoff BL, Byrd CL, Love CJ, et al. Pacemaker lead extraction with the laser sheath: results of the pacing lead extraction with the excimer sheath (PLEXES) trial J Am Coll Cardiol. 1999; 33: 1671-1676

18. Byrd CL, Wilkoff BL, Love CJ et al. Clinical study of the laser sheath for lead extraction: the total experience in the United States Pacing Clin Electrophysiol. 2002; 25: 804-808

19. Neuzil P, Taborsky M, Rezek Z, et al. Pacemaker and ICD lead extraction with electrosurgical dissection sheaths and standard transvenous extraction systems: results of a randomized trial Europace. 2007; 9: 98-104

20. Smith HJ, Fearnot NE, Byrd CL, et al. Five-years experience with intravascular lead extraction. US Lead Extraction Database Pacing Clin Electrophysiol. 1994; 17: 2016-2020

21. Byrd CL, Wilkoff BL, Love CJ, et al. Intravascular extraction of problematic or infected permanent pacemaker leads: 1994-1996. US Extraction Database, MED Institute Pacing Clin Electrophysiol. 1999; 22: 1348-1357

22. Madhavan M, Muhammad R, Paul A et al., Outcomes in patients with cardiovascular implantable electronic devices and bacteremia caused by gram-positive cocci other than Staphylococcus aureus Am. J. Cardiol. 2012; 110:1143-1149

23. Polewczyk A, Jachec W, Tomaszewski A, et al. Lead-related infective endocarditis: factors influencing the formation of large vegetations. Europace. 2017; 19: 1022-1030.

24. Kutarski A, Małecka B, Ząbek A. Mutual abrasions of intracardiac leads - important finding among explanted leads. EUROPACE 2009 June 21-24 Berlin, Germany. Europace 2009; 11 (S2): abstr. 549

25. Kusumoto FM, Schoenfeld MH, Wilkoff BL et al. 2017 HRS expert consensus statement on cardiovascular implantable electronic device lead management and extraction. Heart Rhythm 2017; 14: 503-551.

26. Polewczyk A, Kutarski A, Tomaszewski A, et al. Lead dependent tricuspid dysfunction: Analysis of the mechanism and management in patients referred for transvenous lead extraction. Cardiol J. 2013; 20(4):40210

27. Byrd CL, Schwartz SJ, Hedin NB, Goode LB, Fearnot NE, Smith HJ. Intravascular lead extraction using locking stylets and sheaths. Pacing Clin Electrophysiol. 1990;13:1871-5.

28. Kutarski A, Pietura R, Młynarczyk K, Małecka B, Głowniak A. Pacemaker lead extraction and recapture of venous access: technical problems arising from extensive venous obstruction. Cardiol J. 2012;19:513-7.

29. Kutarski A, Pietura R, Czajkowski M. Difficult dual stage transcutaneous lead extraction complicated by fracture of both leads. Cardiol J. 2012;19:412-7.

30. Kutarski A, Pietura R, Czajkowski M. Breakage of extracted leads: another management option. Kardiol Pol. 2012;70:307-12. 